\title{
Efficient 3D-TLM Modeling and Simulation for the Thermal Management of Microwave AlGaN/GaN HEMT Used in High Power Amplifiers SSPA
}

\author{
Karim Belkacemi ${ }^{1,2, *}$ (1) and Rachida Hocine ${ }^{3}$ \\ 1 Space instrumentation Research Department - Algerian Space Agency - Satellite Development Centre, \\ BP 4065 Ibn Rochd USTO (CDS), Oran 31000, Algeria \\ 2 ECP3M Laboratory Electrical Engineering, Department of Sciences and Technology University of Mostaganem, \\ Mostaganem 27000, Algeria \\ 3 Department of Electronics Engineering, University of Sciences and Technology of Oran Algeria, BP 1505 El \\ M'naeour, Bir El Djir 31000, Algeria; rachida-hocine@univ-usto.dz \\ * Correspondence: kbelkacemi@cds.asal.dz; Tel.: +213-661-264-142
}

Received: 27 April 2018; Accepted: 20 June 2018; Published: 23 June 2018

\begin{abstract}
A three-dimensional thermal simulation investigation for the thermal management of GaN-on-SiC monolithic microwave integrated circuits (MMICs) of consisting multi-fingers (HEMTs) is presented. The purpose of this work is to demonstrate the utility and efficiency of the three-dimensional Transmission Line Matrix method (3D-TLM) in a thermal analysis of high power $\mathrm{AlGaN} / \mathrm{GaN}$ heterostructures single gate and multi-fingers HEMT SSPA (solid state power amplifiers). The self-heating effects induce thermal cross-talk between individual fingers in multi-finger $\mathrm{AlGaN} / \mathrm{GaN}$ that affect device performance and reliability. Gate-finger temperature differences only arise after a transient state, due to the beginning of thermal crosstalk which is attributed to the finite rate of heat diffusion between gate fingers. The TLM method accounts for the real geometrical structure and the non-linear thermal conductivities of $\mathrm{GaN}$ and $\mathrm{SiC}$ in order to improve the realistic calculations accuracy heat dissipation and thermal behavior of the device. In addition, two types of heat sources located on the top of GaN layer are considered in thermal simulations: Nano-scale hotspot as a pulsed wave heat source under gate and micro-scale hotspot as a continuous wave heat source, between gate and drain. Heat diffusion however, occurs not only between individual gate fingers (inter-finger) in a multi-finger HEMT, but also within each gate finger (intra-finger). To compare results, a Micro-Raman Spectroscopy experience is conducted to obtain a detailed and accurate temperature distribution. Good agreement between the microscopic spectral measurement and TLM simulation results is observed by accepting an error less than $2.2 \%$ relative to a maximum temperature. Results show that the 3D-TLM method is suitable for understanding heat management in particular for microwave devices AlGaN/GaN HEMTs SSPA amplifier. TLM method helps to select and locates the expected hot spots and to highlight the need of thermal study pre-design in order to minimize the system-level thermal dissipation and lead therefore to higher reliability.
\end{abstract}

Keywords: AlGaN/GaN HEMTs; SSPA; heat transfer; self-heating; 3D TLM method; Nano-scale hot spots; Raman spectroscopy

\section{Introduction}

The GaN HEMTs (High Electron Mobility Transistor) application is currently growing due to its superior properties, such as high breakdown voltage and high cut-off frequency, which allow designing power switches devices and high efficiency power amplifiers for next generation wireless communication, satellite communication and radar systems [1]. 
The heterojunction AlGaN/GaN-based HEMTs have been recognized as the most promising devices for high-power applications at microwave and millimeter-wave frequency range. However, the ability of generating high RF-output power makes AlGaN/GaN HEMTs an attractive alternative solution compared to traditional GaAs and InP devices [2-4]. GaN takes advantage of the interesting material properties of the III-nitrides, such as wide bandgap $(3.4 \mathrm{eV})$, high breakdown electric field (E $\sim 4.106 \mathrm{~V} / \mathrm{cm}$ ), thermal stability (up to $1250 \mathrm{~K}$ ), excellent thermal conductivity $\left(\mathrm{K}_{\mathrm{GaN}} \sim 1.3 \mathrm{~W} / \mathrm{cm} \cdot \mathrm{K}\right.$ ) and high electron mobility $\left(1600 \mathrm{~cm}^{2} / \mathrm{Vs}\right)[3,4]$. In addition, the essential feature of nitride heterostructures is the formation of two-dimensional electron gas (2DEG) with a high density (ns $\sim 10^{13} \mathrm{~cm}^{-2}$ ) localized at $\mathrm{AlGaN} / \mathrm{GaN}$ interface due to high $\left(\sim 10^{5} \mathrm{~V} / \mathrm{cm}\right)$ spontaneous and piezo-polarization fields that exist in such III-Nitride hetero-structures.

$\mathrm{AlGaN} / \mathrm{GaN}$ high electron mobility transistors grown on $\mathrm{SiC}$ substrate have recently been reported and have developed microwave applications with revealed power densities as high power dissipated exceeding $40 \mathrm{~W} / \mathrm{mm}$ [5-7]. SiC have the best physical and electrical properties such as a thermal conductivity of $(330-490 \mathrm{~W} / \mathrm{m} \cdot \mathrm{K})$, high electron saturation velocity $\left(2.7 \times 10^{7} \mathrm{~cm} / \mathrm{s}\right)$ and high breakdown electric field (up to $3 \times 10^{6} \mathrm{~V} / \mathrm{cm}$ ). Its wide band-gap makes it a more suitable substrate to be used for very high temperature operations (up to $600^{\circ} \mathrm{C}$ ) than Silicon $\left(200^{\circ} \mathrm{C}\right.$ ). Its high thermal conductivity allows these high-power densities to be efficiently dissipated for realistic drain efficiencies to prevent the extreme channel temperatures that would occur due to self-heating with other substrates technologies [8,9]. Moreover, TBR (thermal boundary resistance) at the GaN-substrate interface has an important role in self-heating effects. It is better to have low value, but also to have a realistic temperature-dependent thermal boundary resistance (TBR) between the GaN layer and $\mathrm{SiC}$ substrate [10]. TBR accounts for a large portion of the channel temperature, which may cause about a $100 \mathrm{~K}$ rise in the vertical temperature distribution of the device [11]. Furthermore, as any semiconductor component when GaN HEMTs operate at high power density negative factor appears; localized self-heating in the conducting channel with 2DEG limits the output highest power density and decreases its reliability. The mobility reduces while increasing the temperature as $(1 / T)^{2 / 3}$, resulting in DC and RF performance and creating small high temperature regions called hotspots which can significantly worsen the output characteristic of the HEMT [12].

The HPA (high power amplifiers) based on GaN reliabilities are directly dependent on the maximum operating channel temperature. Therefore, self-heating is a severe problem and is still a limiting factor for device reliability. As such, an accurate estimate for the channel temperature is needed $[13,14]$. In addition to the self-heating effect which occurs in the single finger HEMT, a considered thermal-coupling effect among the neighboring fingers appears in multi-fingers transistors, therefore the thermal analysis becomes more accurate.

Various thermal management solutions, for example, flip-chip bonding, two-phase spray cooling and mounting devices on to substrates, have been attempted. Some other alternatives to dissipate heat have focused on the development of GaN devices on substrates with very high thermal conductivity, such as diamond, but it is not a favorable strategy, due to the large GaN-diamond lattice mismatch, the lack of compatibility of diamond with other substrate materials, and the high expense of the process [15].

Up to now, the temperature measurement of HEMTs could be made with infrared cameras [16], liquid crystal thermography [17], micro-Raman thermography [18], photoluminescence [19], transient thermo-reflectance [20], and pulsed current versus voltage measurements methods. These methods can be expensive and limited by the spatial resolution that may cause problems in measurement precision of the hotspot temperature. Since heat generation is concentrated within a small volume at the drain-side edge of the gate contact, high spatial resolution is required for the measurement of the temperature in the active region of the device. To overcome some of these issues, efficient simulations are necessary [21]. Previous works on self-heating effect in GaN HEMT growth on SiC substrates has been made [22,23]. Numerical solutions are on one hand more commonly followed and a number of accurate simulators have been developed based on finite-volume, finite-difference, 
and finite-element methods [24]. On the other hand, as alternative and powerful numerical tool, transmission line modeling (TLM) has been used to model the thermal behavior of punch-through diodes, TRAPATT diodes, and conducting films on insulating substrates [25-27]. The TLM has already been used successfully to model the thermal behavior of power devices [28]. This method is numerically stable and compares favorably with other numerical techniques in computational expenditure and convenience in modeling complex geometries.

In this paper, we analyzed the thermal characteristics of AlGaN/GaN HEMT's single gate finger, multi-gate finger, and multi-material. We focused in this analysis on a 3-D distribution of the temperature, thermal behavior, self-heating and channel temperature. Furthermore, Micro-Raman Spectroscopy experience method performed by Kuball et al. $[18,22]$ was used to compare the detailed temperature distribution of the device, and the measurements are carried out for the verification of the 3D TLM model. We selected Micro-Raman spectroscopy as the Infrared image technique because of the spatial resolution on the order of $1 \mu \mathrm{m}$, which is required to accurately measure and explore the peak temperature of AlGaN/GaN HEMT with their narrow source-drain opening.

\section{Transmission Line Modeling Method (TLM)}

TLM is a form of finite difference numerical method whose foundations are based on electromagnetic theory. TLM can be used in general to solve the following problems: Diffusion problem [29], Vibration [30], Heat transfer [31], Radar [32], Electromagnetic compatibility [33]. Transmission Line modeling is a space and time discrete method that solves field problems using their electrical circuit equivalent. TLM represents the model as a matrix of transmission lines with voltage pulses traveling through them, which is analogous to flow of heat through a device's material. For propagation in loss medium a pulse wave obeys Maxwell's curl equation on a transmission-line, which had a form to the telegrapher's equation [34]:

$$
\nabla^{2} \varnothing=2 \alpha \cdot R_{d} C_{d} \frac{\partial \varnothing}{\partial t}+\alpha \cdot L_{d} C_{d} \frac{\partial^{2} \varnothing}{\partial t^{2}}
$$

where:

$\Phi:$ is the potential depends on $(x, y, z, t)$.

$R_{d}, C_{d}, L_{d}$ : are distributed line elements; the Resistance, the Capacitance and the Inductance per unit length respectively.

$\alpha$ : is the constant, may take $\alpha=1,2,3$ for $1 \mathrm{D}, 2 \mathrm{D}$, and 3D.

Steady state and transient thermal responses of integrated circuit (IC) devices are determined by solving of the heat flow nonlinear basic equation given by [31]:

$$
\nabla^{2} T=\frac{\rho \cdot C_{p}}{K_{t}(T)} \cdot\left(\frac{\partial T}{\partial t}\right)
$$

where:

$K_{t}(T)$ : is the temperature-dependent thermal conductivity.

$C_{p}$ : is a specific heat of the material.

$\rho:$ is the material density.

In Equation (1), when $R_{d}=0$ (medium without loss), this equation becomes identical to a wave one. If $R_{d} \neq 0$ (lossy) the equation describes an attenuated wave, and therefore, Equation (2) establishes an equivalence with thermal diffusion process, if the first time derivate term in the right-hand side of the Equation (1) dominates the second time derivate term. By using TLM network to model the thermal heat flow in terms of lumped RLC network, the combinations of capacitor and inductance per unit length $\left(C_{d}, L_{d}\right)$ will be replaced by loss-free transmissions-lines, involving impedance $Z$, which connect 
each node to its neighbors and carry voltage pulses between the nodes during a time step $\Delta t$. Hence, it may be possible to model the heat transfer processes in terms of a lumped elements $R_{d}, C_{d}$ network where temperature is represented by voltage and heat by current [35]. According to the fundamental transmission line matrix theory, impedance $Z$ is given by the following equation:

$$
Z=\sqrt{\frac{L}{C}}=\frac{3 \cdot \Delta t}{C}=\frac{L}{3 \cdot \Delta t}
$$

In TLM 3D modeling, the system is divided in small volumes elements. Each element is represented by a node that represents a unit of a line transmission. Figure 1 represents a single volume three dimensional TLM node $(x, y, z)$.

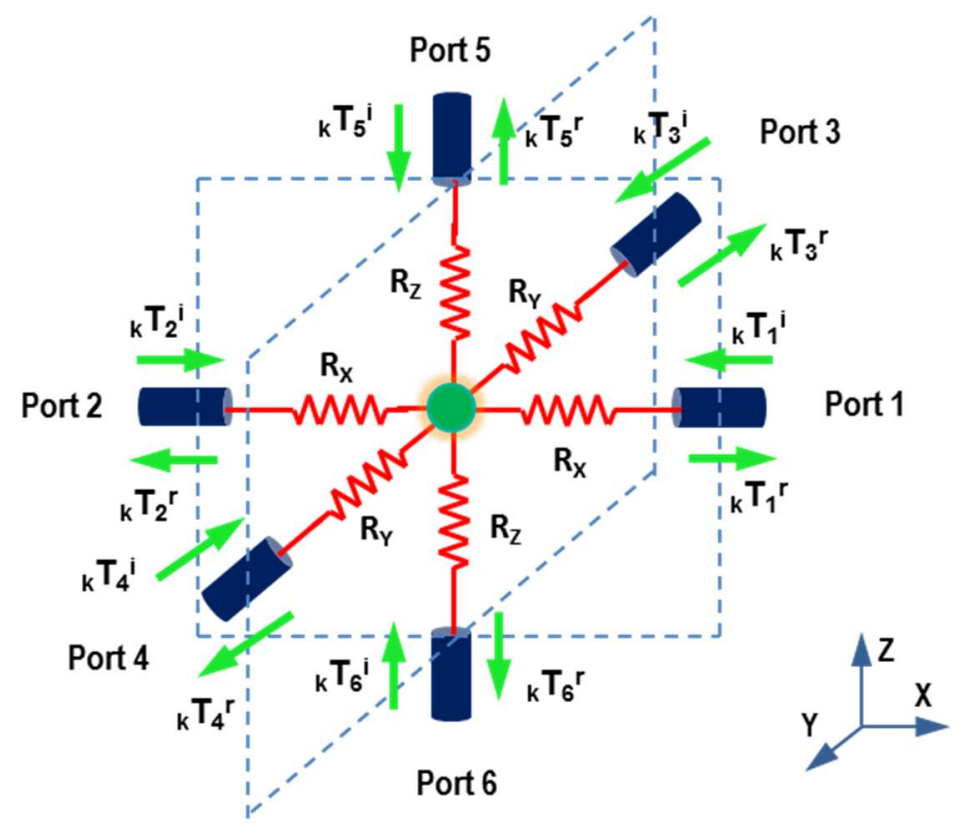

Figure 1. TLM 3D Single volume node.

Each element of length $\Delta x, \Delta y, \Delta z$, represents spatial discretization. Using analogy between Equations (1) and (2), the values of three-dimensional $R$ and a common $C$ at each node are defined by:

$$
R_{x}=\frac{\Delta x}{2 \cdot K_{t} \cdot \Delta_{y} \cdot \Delta_{z}}, R_{y}=\frac{\Delta y}{2 \cdot K_{t} \cdot \Delta_{x} \cdot \Delta_{z}}, R_{z}=\frac{\Delta z}{2 \cdot K_{t} \cdot \Delta_{x} \cdot \Delta_{y}}, C=\rho \cdot C_{p} \cdot \Delta x \cdot \Delta y \cdot \Delta z
$$

As we have a cubic elemental volume, the three local distances between nodes are equidistant, that means; $\Delta x=\Delta y=\Delta z$.

The TLM is an iterative method. Injection of delta temperature pulses is to be incident simultaneously after each time step $\Delta t$ on all parts of all nodes of the network. During $\Delta t$, the incident temperature pulses are scattered instantaneously into reflected pulses which travel along link transmission and become new incidents upon neighboring nodes. We can note that in the network, a TLM routine operates on the traveling, scattering and connecting of these thermal pulses. On Figure 1 incident and scattered pulses on each numbered port are labeled ${ }_{k} T_{j}^{i}$ with $j$ indicating the direction and $k$ the $k^{\text {th }}$ iteration. When we apply the fundamental theorems of electricity to the TLM node $(n)$, the nodal temperature at $k^{\text {th }}$ iteration is given by the following equation [36,37]:

$$
{ }_{k}^{0} T(n)=\left[\frac{2\left({ }_{k} T_{1}^{i}+{ }_{k} T_{2}^{i}\right)}{R_{x}+Z}+\frac{2\left({ }_{k} T_{3}^{i}+{ }_{k} T_{4}^{i}\right)}{R_{y}+Z}+\frac{2\left({ }_{k} T_{5}^{i}+{ }_{k} T_{6}^{i}\right)}{R_{z}+Z}+I(n)\right] \cdot \frac{1}{Y}
$$


where, $Z$ is the characteristic impedance: $Z=3 \Delta t / C$ and $I(n)$ is the heat source generator and $Y$ is the admittance which is given by:

$$
Y=\frac{2}{R_{x}+Z}+\frac{2}{R_{y}+Z}+\frac{2}{R_{z}+Z}
$$

Scattered thermal pulses are the reflected pulses ${ }_{k} T_{j}^{r}$ calculated from a circuit analysis of the nodes that gives the followings equations:

$$
\begin{aligned}
& { }_{k} T_{1}^{r}(x, y, z)=\frac{1}{R_{x}+Z}\left[Z \cdot{ }_{k}^{0} T(x, y, z)+\left(R_{x}-Z\right) \cdot{ }_{k} T_{1}^{i}(x, y, z)\right] \\
& { }_{k} T_{2}^{r}(x, y, z)=\frac{1}{R_{x}+Z}\left[Z \cdot{ }_{k}^{0} T(x, y, z)+\left(R_{x}-Z\right) \cdot{ }_{k} T_{2}^{i}(x, y, z)\right] \\
& { }_{k} T_{3}^{r}(x, y, z)=\frac{1}{R_{y}+Z}\left[Z \cdot{ }_{k}^{0} T(x, y, z)+\left(R_{y}-Z\right) \cdot{ }_{k} T_{3}^{i}(x, y, z)\right] \\
& { }_{k} T_{4}^{r}(x, y, z)=\frac{1}{R_{y}+Z}\left[Z \cdot{ }_{k}^{0} T(x, y, z)+\left(R_{y}-Z\right) \cdot{ }_{k} T_{4}^{i}(x, y, z)\right] \\
& { }_{k} T_{5}^{r}(x, y, z)=\frac{1}{R_{z}+Z}\left[Z \cdot{ }_{k}^{0} T(x, y, z)+\left(R_{z}-Z\right) \cdot{ }_{k} T_{5}^{i}(x, y, z)\right] \\
& { }_{k} T_{6}^{r}(x, y, z)=\frac{1}{R_{z}+Z}\left[Z \cdot{ }_{k}^{0} T(x, y, z)+\left(R_{z}-Z\right) \cdot{ }_{k} T_{6}^{i}(x, y, z)\right]
\end{aligned}
$$

These reflected thermal pulses after a time $\Delta t$ travel to adjacent nodes along a transmission line joining two neighboring nodes (left and right) and become new incident thermal pulses. So, at $(k+1)$ iteration, this incident thermal pulse is due to impedance mismatch by reflections at discontinuities. It is computed as follows:

$$
{ }_{k+1} T_{j}^{i}(x, y, z)=\Gamma_{j}(x, y, z)_{k} T_{j}^{r}(x, y, z)+\left[1-\Gamma_{j}(u, v, w)\right]_{k} T_{p}^{r}(u, v, w)
$$

where $\Gamma_{j}(x, y, z)$ is the reflection coefficient in direction $j$ at concerned node, and it is calculated as follows:

$$
\Gamma_{j}(x, y, z)=\frac{Z(u, v, w)-Z(x, y, z)}{Z(u, v, w)+Z(x, y, z)}
$$

where the corresponding values of the directions $j, p$, and positions $u, v, w$ are mentioned in Table 1 .

Table 1. Corresponding values of $j, p, u, v, w$.

\begin{tabular}{ccccc}
\hline Directions & \multicolumn{3}{c}{ Positions } \\
\hline $\boldsymbol{j}$ & $\boldsymbol{p}$ & $\boldsymbol{u}$ & $\boldsymbol{v}$ & $\boldsymbol{w}$ \\
\hline 1 & 2 & $x-1$ & $y$ & $z$ \\
2 & 1 & $x+1$ & $y$ & $z$ \\
3 & 4 & $x$ & $y-1$ & $z$ \\
4 & 3 & $x$ & $y+1$ & $z$ \\
5 & 6 & $x$ & $y$ & $z-1$ \\
6 & 5 & $x$ & $y$ & $z+1$ \\
\hline
\end{tabular}

In the case of reflection coefficient $\Gamma_{j}(x, y, z)=0$ that conduct to the impedance matching, $Z(u, v, w)=Z(x, y, z)$, the six incident thermal pulses at $(k+1)^{\text {th }}$ iteration are deduced from Equation (13)

$$
{ }_{k+1} T_{j}^{i}(x, y, z)={ }_{k} T_{p}^{r}(u, v, w)
$$


To resolve the problem of heat diffusion by TLM-3D, we can exploit and evaluate numerically a repeated set of Equations (4)-(15). It is necessary for numerical calculation by TLM to take in account the boundary conditions shown in Figure 2. It is considered as a part of the heat diffusion model that describes the limits interaction of the physical model with its surroundings, and also should be consistent with the description of heat transport inside the medium [38].

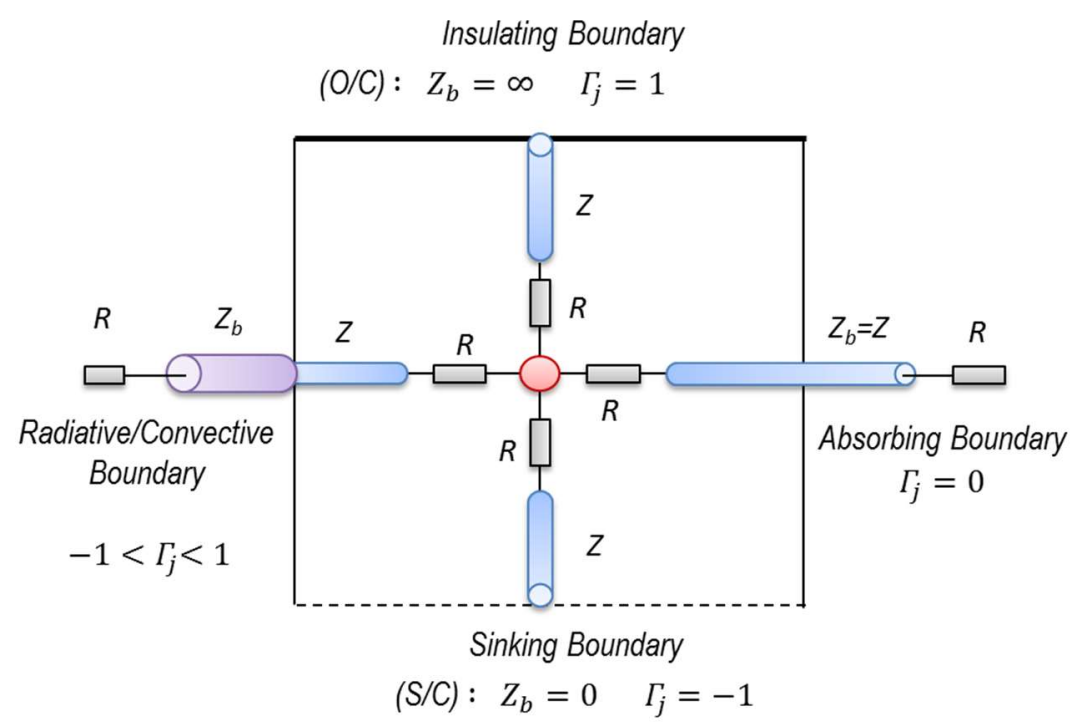

Figure 2. TLM Boundary conditions principle.

For sinking boundary (bottom view), any incident heat pulse on the boundary is reflected as equal in magnitude and reversed in phase. It corresponds to an electrical short-circuit $(S / C)$ where the reflected coefficient $\Gamma_{j}=-1$. For heat insulating boundary (top view), any incident heat pulse is reflected as equal in magnitude and phase. This case corresponds to an electrical open-circuit $(\mathrm{O} / \mathrm{C})$ where the reflected coefficient $\Gamma_{j}=1$. A symmetry boundary is presented by an electrical open-circuit in TLM modeling [35-38].

\section{GaN HEMT Device on MMIC Die}

Monolithic Microwave Integrated Circuits (MMICs) based on AlGaN/GaN high electron mobility transistors (HEMTs) are usually used in aircraft, land vehicles, satellite application and other multifunctional RF systems. Thermal analysis of HEMT structures for MMICs is important due to increased circuit packing densities and RF output powers. Solid state power amplifier SSPA may consist of one or more MMIC chips. In illustration [39], an example of a RF 50 W SSPA is shown which consists of four (4) MMIC chips, each of which develops $12.5 \mathrm{~W}$ with 50\% PAE (power added efficiency), and are combined by a lossless circuit in the output. Each chip has 8 multi-gate amplifiers and each amplifier includes ALGaN/GaN HEMT with eight (8) gate fingers of $1.56 \mathrm{~W}$ power amplifier (i.e., $8 \times 1.56 \mathrm{~W}$ ). Thanks to a lossless combiner the 4 MMIC chips produce nearly a $50 \mathrm{~W}$ output power, and for cooling and efficiency thermal dissipation, these 4 chips are assumed to be soldered onto a heat sink. Figure 3 below shows a concept described of a GaN MMIC chip. 
(a)

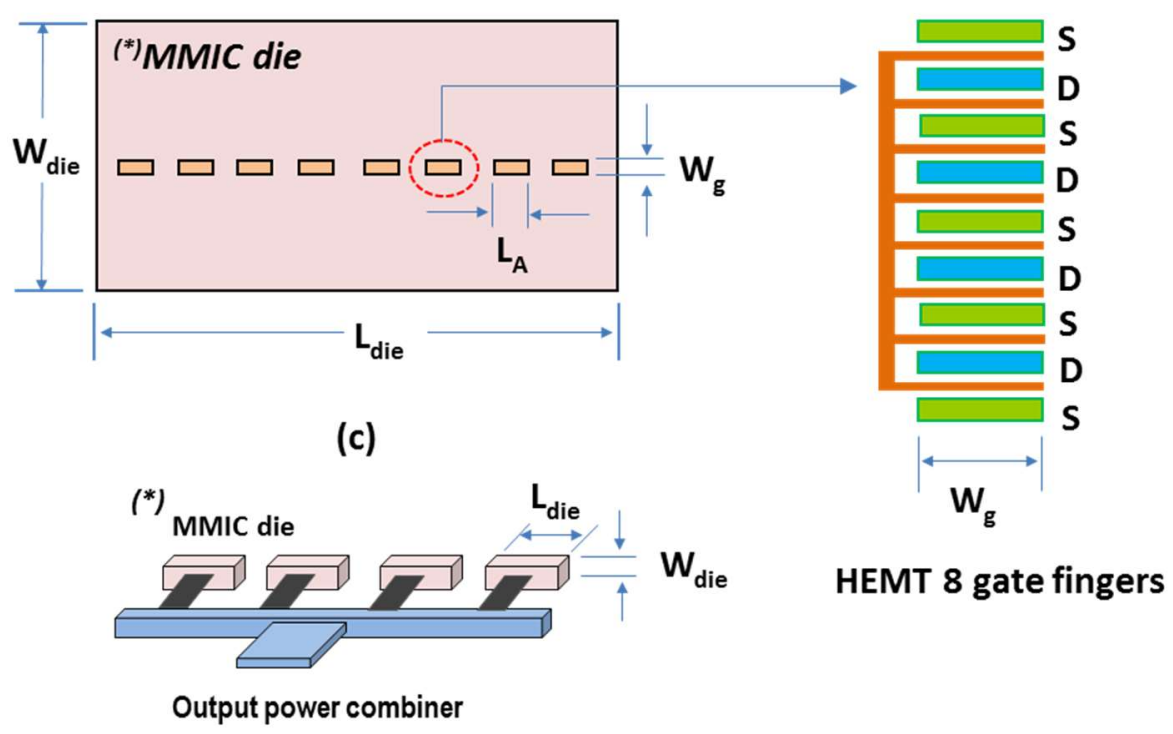

Figure 3. Model described of a GaN MMIC chip. (a) Schematic diagram of a $12.5 \mathrm{~W}$ AlGaN/GaN MMIC die; (b) $1.56 \mathrm{~W}$ power amplifier HEMT consisting of 8 gate fingers structure; (c) $50 \mathrm{~W}$ SSPA $\left(4 \times 12.5 \mathrm{~W}\right.$ MMIC die). ${ }^{*}$ is mentioned in the (a) showing one chip. In the (C), 4 chips of (a) is presented.

\subsection{Device Description's Model}

For the thermal analysis of a multi-fingers AlGaN/GaN HEMT die, Figure 4 shows the dimension geometry, with its geometrical parameters listed in Table 2 [40]. The epitaxial layers were grown by MOCVD on the semi insulating $\mathrm{SiC}$ substrates. In its vertical direction, the substrate is a silicium carbide $\mathrm{SiC}$ of $350 \mu \mathrm{m}$ in thickness, while the die attach layer is a Sn-3.5Ag of $50 \mu \mathrm{m}$ in thickness. The thickness of metallization layout (Au), $\mathrm{AlGaN}$ ( $23 \%$ of Aluminum), and the $\mathrm{GaN}$, are selected to be $2,0.03$, and $2 \mu \mathrm{m}$, respectively. The die is attached to a Cu-tungsten micro channel heat-sink for efficient thermal management. The device is passivated by $\mathrm{SiO} 2$ layer, which is omitted in thermal simulations.

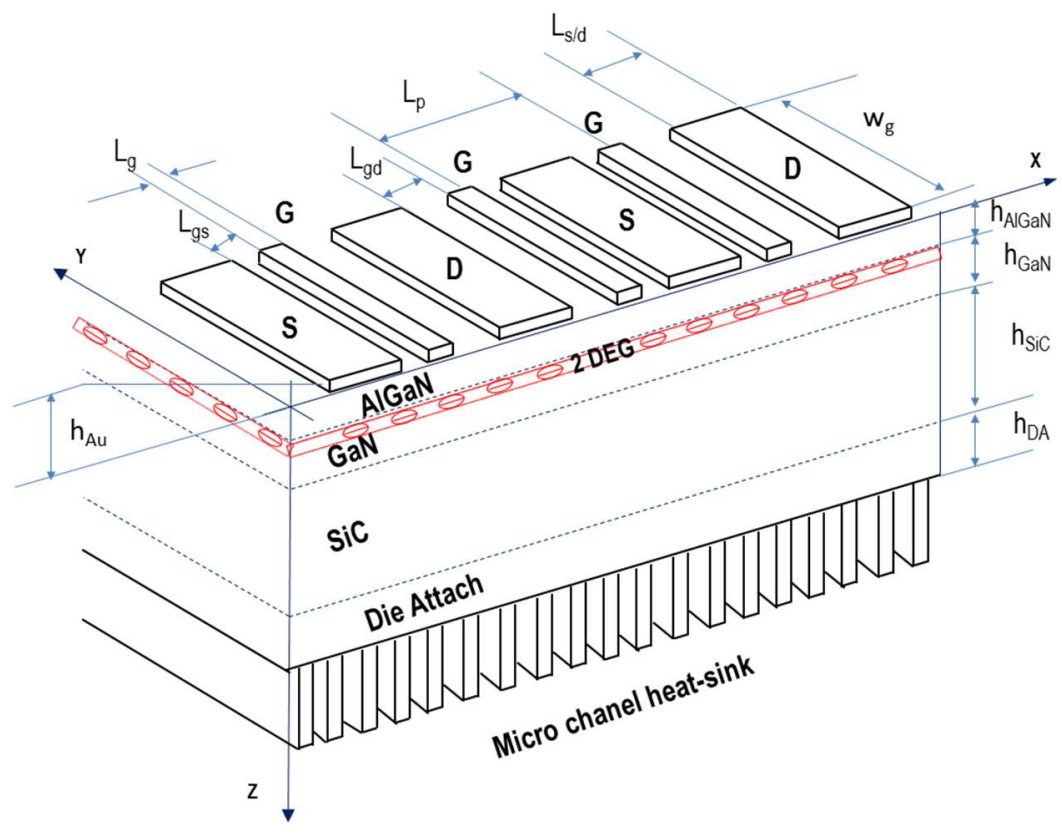

Figure 4. 3D cross section view of the AlGaN/GaN HEMT die. 
Table 2. Geometrical parameters of MMIC and AlGaN/GaN HEMT.

\begin{tabular}{cc}
\hline Definitions of Geometrical Parameters & Value $(\mu \mathrm{m})$ \\
\hline Length of MMIC die: Ldie & 5500 \\
Width of MMIC die: Wdie & 430 \\
Length of HEMT: LA & 360 \\
Width of HEMT: Wg & 250 \\
Drain, source lengths: Ld/s & 20 \\
Drain/source-gate spacing: Lgd/Lgs & $2.8 / 0.8$ \\
Gate-to-gate spacing pitch: Lp & 25 \\
Gate length: Lg & 0.8 \\
Thickness of metallization layer: hAU & 2 \\
AlGaN buffer thickness: hAlGaN & 0.03 \\
GaN layer thickness: hGaN & 2 \\
SiC layer thickness: hSiC & 350 \\
Die attach Sn-3.5Ag thickness: hdie & 50 \\
\hline
\end{tabular}

In GaN devices, the total heat generated is equal to $I_{d S} V_{d S}$, which is the power in the device, leading to large quantities of heat generation.

During RF operation under high-voltage, the current flows from the drain fingers to the source fingers and is modulated by the voltages applied to the gate fingers. Therefore, localized self-heating increases the channel temperature and happens in a region near the gate contact inside the most majority multi-finger HEMT structure.

\subsection{Materials Parameters}

Most materials inserted in the AlGaN/GaN HEMT, are temperature-dependent, in particular for thermal conductivity $K_{t}(\mathrm{~W} / \mathrm{m} \cdot \mathrm{k})$ and other parameters such as thermal expansion coefficient $\alpha(\mathrm{ppm} / \mathrm{k})$, electrical conductivity $\sigma(\mathrm{S} / \mathrm{m})$. However, the material density $\rho\left(\mathrm{kg} / \mathrm{m}^{3}\right)$ and specific heat $C_{p}(\mathrm{~J} / \mathrm{kg} \cdot \mathrm{k})$ are not sensitive to temperature variation, and they can be used for simulation as constants. A range of the related material properties is shown in Table 3 [40].

Table 3. Material parameters used for AlGaN/GaN HEMT.

\begin{tabular}{|c|c|c|c|}
\hline Materials & $\begin{array}{c}\text { Thermal Conductivity } \\
K_{t}(\mathrm{~W} / \mathrm{m} \cdot \mathrm{k})\end{array}$ & $\begin{array}{l}\text { Heat Capacity } \\
C_{p}(\mathrm{~J} / \mathrm{kg} \cdot \mathrm{K})\end{array}$ & $\begin{array}{c}\text { Mass Density } \rho \\
\left(\mathrm{kg} / \mathrm{m}^{3}\right)\end{array}$ \\
\hline $\mathrm{Au}$ (Top) & 320 & 229.1 & 19,300 \\
\hline $\mathrm{AlGaN}$ & 30 & 490 & 6070 \\
\hline GaN & $\mathrm{K}_{\mathrm{t}}(\mathrm{T})=150 \times(300 / \mathrm{T})^{1.42}$ & 490 & 6150 \\
\hline $\mathrm{SiC}$ & $\mathrm{K}_{\mathrm{t}}(\mathrm{T})=387 \times(300 / \mathrm{T})^{1.49}$ & 750 & 3100 \\
\hline Die-Attach & 33 & 220 & 3379 \\
\hline Baseplate & 180 & 722 & 2980 \\
\hline
\end{tabular}

\section{Experimental Measurements by Micro-Raman Spectroscopy}

Several papers over the last few years have discussed the critical impact of the self-heating evaluation for the AlGaN/GaN HEMTs. Since heat is generated only on the surrounding of the gate and because of the sub-micrometer gate-length dimension, accurate temperature measurement requires spatial resolution on a length scale of $1 \mu \mathrm{m}$ or less. This measurement can be achieved using a micro-Raman Spectroscopy that offers the opportunity to quantify channel temperature and mapping the temperature distribution in the devices with spatial resolution nearly in range [0.5-0.8] $\mu \mathrm{m}$. Kuball et al. were able to measure local temperature right at the channel with an approximately $1 \mu \mathrm{m}$ resolution without any effect of perturbation of the transistor during operation. The concept of temperature measurement of AlGaN/GaN HEMTs by micro-Raman Spectroscopy is based on the temperature dependence of the phonon frequencies of the GaN crystal. This measurement technique 
uses a Renishaw micro-Raman system with $488 \mathrm{~nm}$ line of an $\mathrm{Ar}^{+}$ion laser as excitation source. More details about the use of micro-Raman Spectroscopy for active device temperature measurements can be found in References $[18,22,23,41]$. As part of the aim of measuring the profile temperature distribution by micro-Raman spectroscopy, a Radio Frequency amplifier for satellite applications, operating in S-band (2-4 GHz), was taken as described in Figure $3 \mathrm{~b}$. The device is a multi-finger $\mathrm{AlGaN} / \mathrm{GaN}$ HEMT on $\mathrm{SiC}$ substrate with 8 gates, operated under DC drain bias voltages $\mathrm{Vds}=20 \mathrm{~V}$, Ids $=625 \mathrm{~mA}$ at $\mathrm{Vgs}=0 \mathrm{~V}$. As part of the purpose of verifying the slope form and the thermal behavior of this device under test, we have reproduced the experience result curve point by point to better view and extract the maximum peak temperatures. The thermal profile is shown in Figure 5. The measured channel temperature was approximately equal to $225^{\circ} \mathrm{C}$.

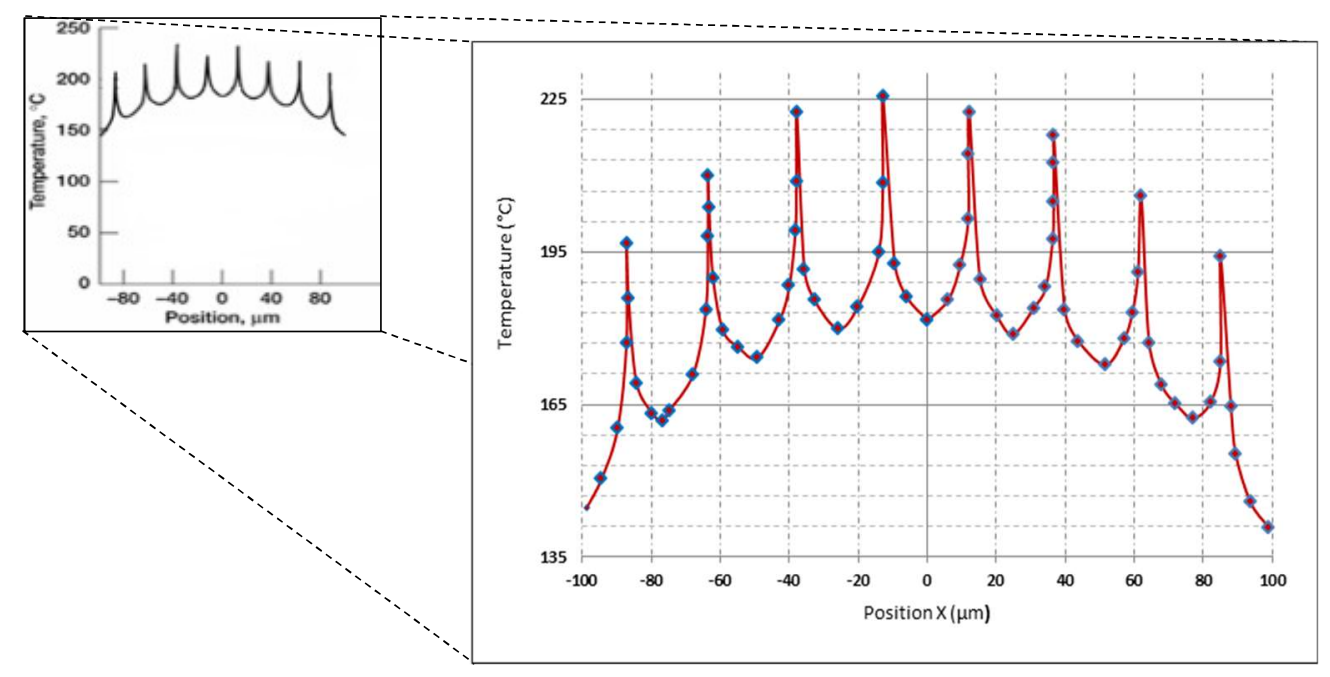

Figure 5. Raman Spectroscopy Thermal profile of an 8 gate AlGaN/GaN HEMT measured [22].

\section{Simulation Results and Discussion}

The first simulations were carried out by TLM-3D for the whole structure using the Maple language in order to evaluate the temperature at every node within the device, (see Figure 6).

In 3D-TLM modelling process, matrices of temperature of incident and scattered pulses, transmission-line impedances, and thermal resistances need to be stored separately, and therefore the temperature at any node within the device can be evaluated as a function of time. For representation in $X-Y$ plan view, nodes are assigned to the position in $X$-axis and $Y$-axis. Spatial discretization $\Delta x$ and $\Delta y$ are selected to be $2 \mu \mathrm{m}$ and $12.5 \mu \mathrm{m}$ respectively for the whole HEMT structure device. The total input power dissipated in whole device is $12.5 \mathrm{~W}$, then corresponding to a power density of $7 \mathrm{~W} / \mathrm{mm}$ injected [22]. Due to the thinness of the conductive channel, the heat source can be typically treated as a set of surface heat fluxes applied to areas corresponding to the size $\left(\mathrm{W}_{\mathrm{g}} \times \mathrm{Lg}_{\mathrm{g}}\right)$ at each gate finger. The heat source is due to the strong electric field located at the gate edge area near the AlGaN/GaN interface layer. A micro-channel heat-sink temperature was assumed to be $300{ }^{\circ} \mathrm{K}$. Under same bias conditions, a comparison is made between the device channel temperatures simulation by TLM method and the micro-Raman Spectroscopy measurements. We observe a hot-area with maximum temperature which is equal approximately to $230.21^{\circ} \mathrm{C}$. However, a little difference temperature value as $\Delta T \approx 5^{\circ} \mathrm{C}$, is observed between experience measurement and 3D-TLM simulations.

In the most thermal modelling works, researchers are usually taking a half and/or a quarter views of devices structure due to of the device symmetry. However, in TLM simulations, we can take whole system to be simulated. This is among the advantage and efficiency of 3D-TLM method. 


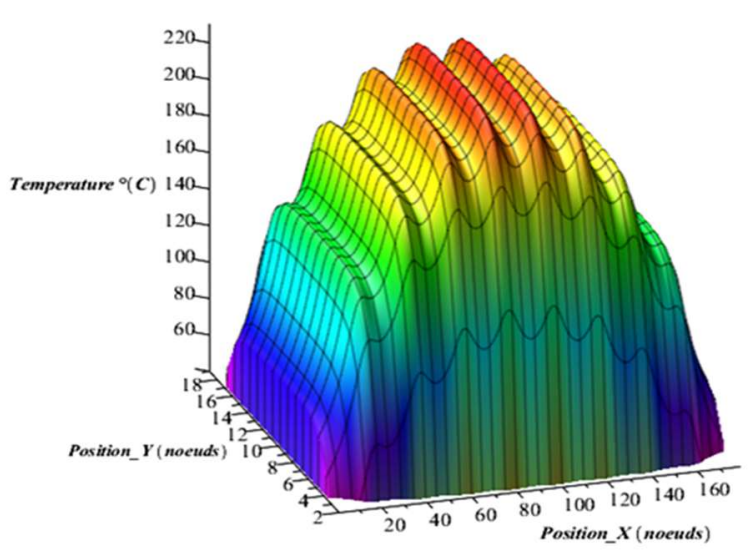

(a)

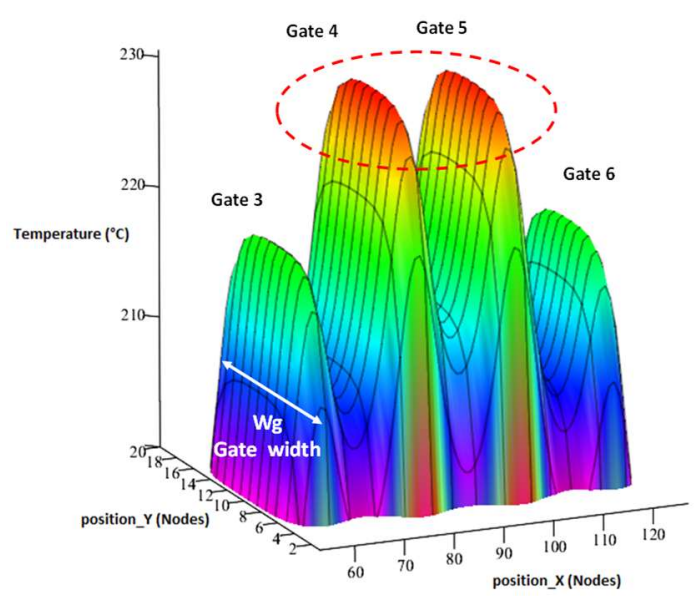

(c)

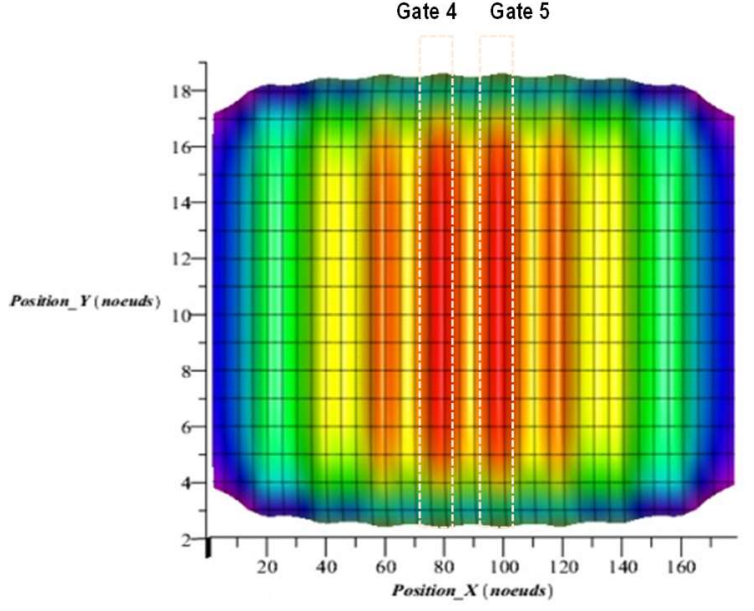

(b)

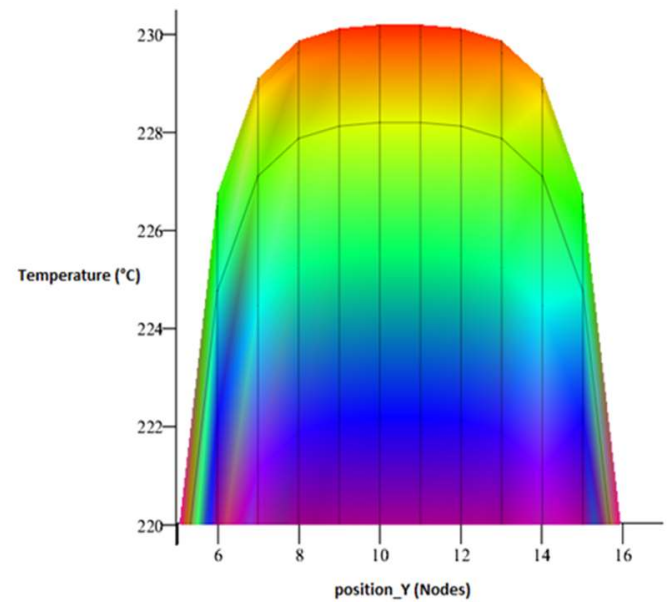

(d)

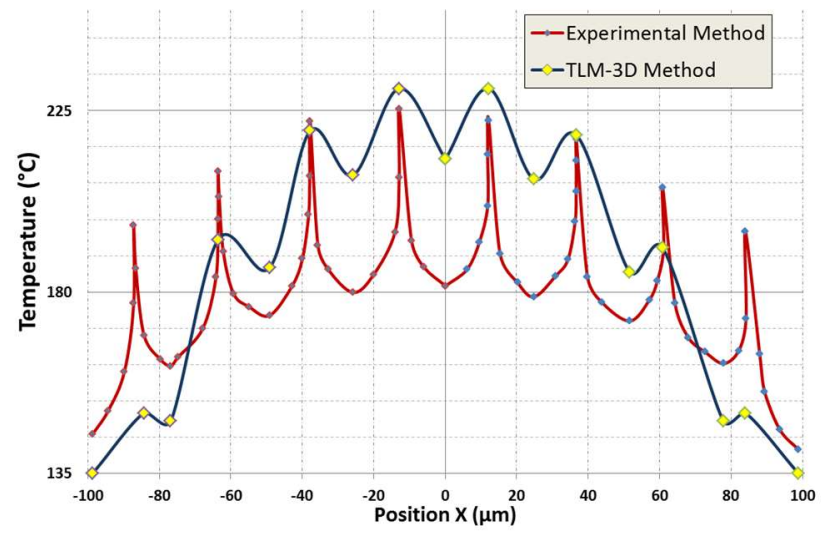

(e)

Figure 6. (a) 3D-TLM simulation view of the whole structure device; (b) $X-Y$ plan view showing the hottest region gate 4 \& gate 5; (c) simulated temperature distribution (gate finger width) in device center gate along finger for $(8 \times 250) \mu \mathrm{m} \mathrm{AlGaN/GaN} \mathrm{HEMT} \mathrm{device;} \mathrm{(d)} \mathrm{Y-axis} \mathrm{view;} \mathrm{(e)} \mathrm{Comparison}$ between 3D-TLM simulation and experimental results.

The thermal profile simulated by TLM method in two dimensions (2-D) is shown in Figure 6a. As we observe a hot-area with maximum temperature equal approximately to $230.21^{\circ} \mathrm{C}$, located at the center of the device and which is assigned by the two gates 4 and 5 . The peak temperature 
occurs in the multi-finger (8-gate) device center, and decreases towards the device edges. Since the temperature in the central source-drain portion is higher than in the source-drain portion located closer to the multi-finger device edges, thermal coupling is clearly apparent. Reasonable agreement relative to the maximum temperature between micro-Raman experiment and TLM-3D simulation is achieved. However, a little difference temperature value as $\Delta T \approx 5{ }^{\circ} \mathrm{C}$, is observed between experience measurement and 3D-TLM simulation by accepting an error less than $2.2 \%$ according to Figure 6e. Heat is generated in the conducting channel of the device near the GaN top surface layer, whereas experience Raman spectroscopy measures the average temperature of the GaN layer and consequently the peak channel temperature is underestimated. Moreover, heat transfer across interfaces inside the semiconductor devices, including the impact on material imperfections such as dislocations [42], are essential both for microwave and for power switching devices [43].

Figure 6. shows a three-dimensional view preceded by TLM simulation that represents a thermal distribution of a whole 8-gate AlGaN/GaN HEMT structure ( $\left.\mathrm{L}_{\mathrm{HEMT}} \mathrm{XW}_{\mathrm{HEMT}}\right)$. We observe that temperature distribution behaves non-uniformly along the gate length.

The simulated temperatures distribution (gate finger width) in device center gate along finger for $(8 \times 250) \mu \mathrm{m} \mathrm{AlGaN} / \mathrm{GaN}$ HEMT device is presented in Figure $6 \mathrm{c}$, d illustrates the $Y$-axis view. The results show the non-uniform behavior of the temperature distribution with a significant temperature variation along the length of the gate finger and a maximum temperature at the HEMT center.

We can observe clearly at the top of the HEMT (see Figure $6 \mathrm{~b}$ ), the centers are the hottest surface characterized by gates 4 and 5 . Indeed, for an HEMT having multiple fingers, the outer fingers are the coolest and the fingers in the middle are the hottest. Therefore, self-heating is induced leading to thermal cross-talk (thermal coupling) between individual gate fingers. This effect becomes serious if it persists and leads to the degradation of device performance or an irreversible damage and this is compared with similar results in the literature using TCAD simulator tool according to Figure 7 and good agreement is achieved [44-46].

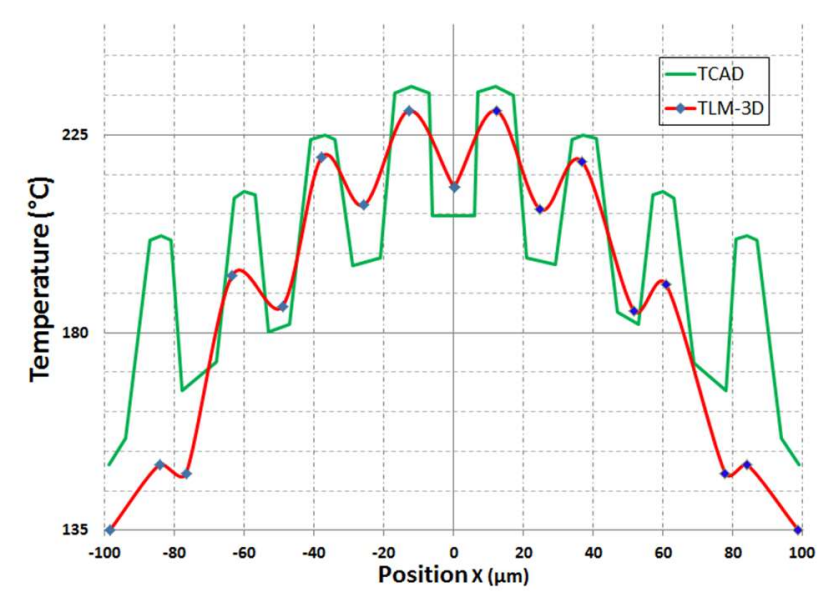

Figure 7. Comparison between 3D-TLM and electro-thermal (TCAD) simulation.

In the aim to study the impact of heat excitation modeling, for the active region represented by a HTL Hotspot Temperature Line, two types of heat sources located on the top of GaN layer are considered (Figure 8):

- Nano-scale hotspot heat source considered as a pulsed heat source, under gate and described by a square $50 \mathrm{~nm} \times 50 \mathrm{~nm}$.

- Micro-scale hotspot heat source considered as a continuous wave heat source, between gate and drain and described by $\mathrm{L}_{\mathrm{gd}} \times 0.4 \mu \mathrm{m}$ section. 


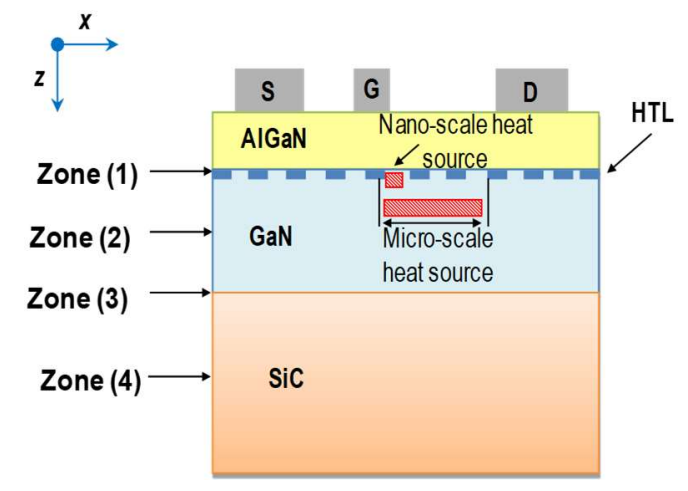

Figure 8. Illustration of Hotspot Temperature Line (HTL) heat source.

In Z-direction, four zones are chosen for the evaluation temperature distribution in this TLM study. Zone (1) is the active region; it is the position where electrons flow between the drain and the source through a channel. Zone (2) is a position corresponding to the middle of GaN buffer layer, Zone (3) is a position corresponding to the interface layer $\mathrm{GaN} / \mathrm{SiC}$, and Zone (4) is a position corresponding to the substrate $\mathrm{SiC}$ layer.

Figure 9 shows the temperature distribution along the $x$-axis at 4 zones. Through different device layers, TLM simulation provides a thermal behavior and detailed information on heat management in each layer node by node. Besides, we observe along the vertical position (Z-direction) a change in slope that specify a dynamic heat transfer and each layer is specified by a color. The high temperature layer in the device is localized in the top one, where temperature is higher than the one founded in the GaN layer. In the bottom is the $\mathrm{SiC}$ layer (the green one) where the temperature is lower, which is the high thermal conductivity of the substrate that allows for the diffusing of the heat from the top to the heatsink, evacuating away the generated heat.

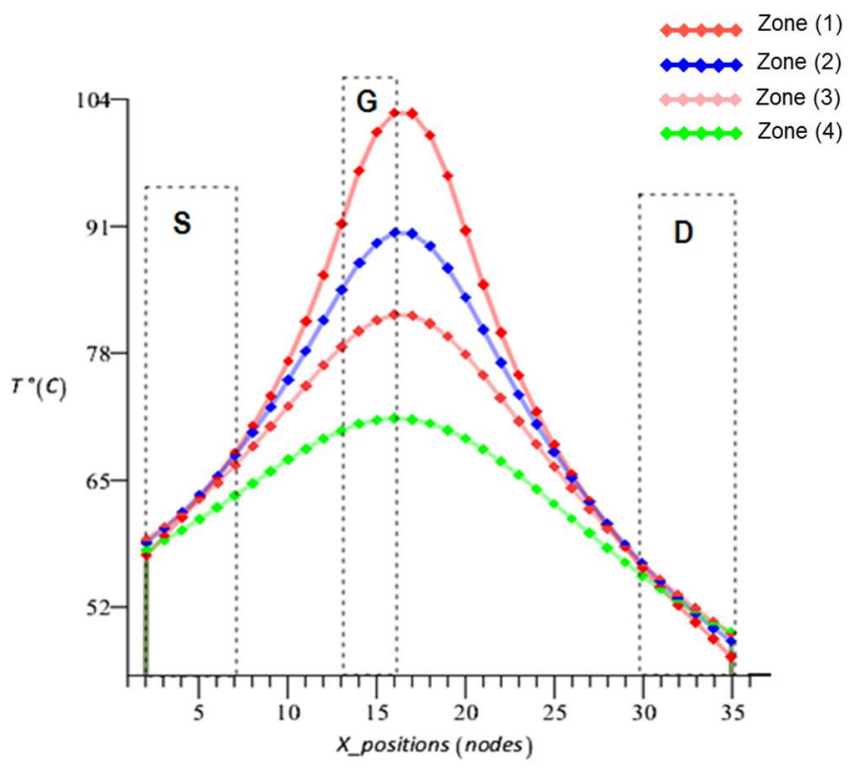

Figure 9. Thermal profile along the vertical position (Z-direction) for single gate.

3D-TLM results along the vertical position (Z-direction) for the four zones are shown in Figure 10. This simulation is used to map the surface temperature distribution and predict the expected and risked hot spots in the device. The results by TLM-3D simulation show that temperatures measured on the substrate of $\mathrm{SiC}$ are lower than those of the $\mathrm{GaN}$ layer. The substrate (green one layer) is 
effectively evacuating the generated heat. As we can notice, the thermal interaction between the individual gate finger and the so called thermal cross-talk causes an additional temperature rise above that of single isolated fingers. The maximum gate finger temperature occurs at the center of the device, leading to self-heating phenomena, and decreases towards the outer fingers. This is a characteristic of thermal cross-talk in multi-finger devices. Self-heating induced thermal cross-talk between individual fingers is important, affecting channel temperatures, then device performance and device reliability. Heat diffusion, however, occurs not only between individual gate fingers (inter-finger) in a multi-finger HEMT, but also within each gate finger (intra-finger).

Figure 11 shows the temperature distribution for uniform spacing 8-fingers HEMT. The results indicate clearly, that the heat generated during the operation mainly flows through the GaN and SiC layers to heatsink. The temperature-dependent of thermal conductivity is introduced in TLM-3D simulation.

The influence on the GaN layer on channel temperature is less significant since the GaN and $\mathrm{AlGaN}$ layers are really thin compared to SiC's. Furthermore, the thermal conductivity of SiC plays a significant and decisive role in the thermal behavior of the AlGaN/GaN HEMT device.

Simulation results obtained using temperature-dependent thermal conductivity for GaN were observed to differ only slightly (less than $5^{\circ} \mathrm{C}$ ) from the results obtained using the thermal conductivity of $\mathrm{GaN}+\mathrm{SiC}$ as implemented in the current study.

As a consequence, the thermal conductivities of the materials are key parameters of the thermal model behavior, and the temperature gradient in the $\mathrm{SiC}$ is mostly directed to the heatsink.

On the other hand, introducing Nano-scale excitation heat source in TLM simulations showed that channel temperature is much more increased compared to the Micro-scale excitation heat source results. This is due to the fact that the Nano-scale hotspot heat source is considered as a pulsed wave heat source, under gate and described by a square $50 \mathrm{~nm} \times 50 \mathrm{~nm}$ and the heating pulses follow one another so closely that the junction AlGaN/GaN cannot cool down to its initial temperature during each cycle, adding to the self-heating induced by thermal cross-talk between individual fingers of the device.

The thermal behavior of AlGaN/GaN-based devices strongly depends on the value of thermal conductivity of various materials on which its structures are grown. But diffusivity alone is not a wholly valid parameter by which to select materials. The effect of the $\left(\rho^{*} \mathrm{Cp}\right)$ product (the heat necessary to raise the temperature of a unit volume of material) has a significant effect on the thermal profiles within miniaturized high-power amplifiers. So, the heat generated by the heat sources is transmitted to the edge of $\mathrm{AlGaN} / \mathrm{GaN}$ interface through horizontal heat spreading and reduces the heat gathered around the heat source.

The miniaturization of high power amplifiers SSPA creates problems of heat dissipation. Simulation presents peculiar challenges due to the need for the detailed modelling of devices. The TLM method is a powerful tool for analyzing thermal effects and modelling heat diffusion problems. 


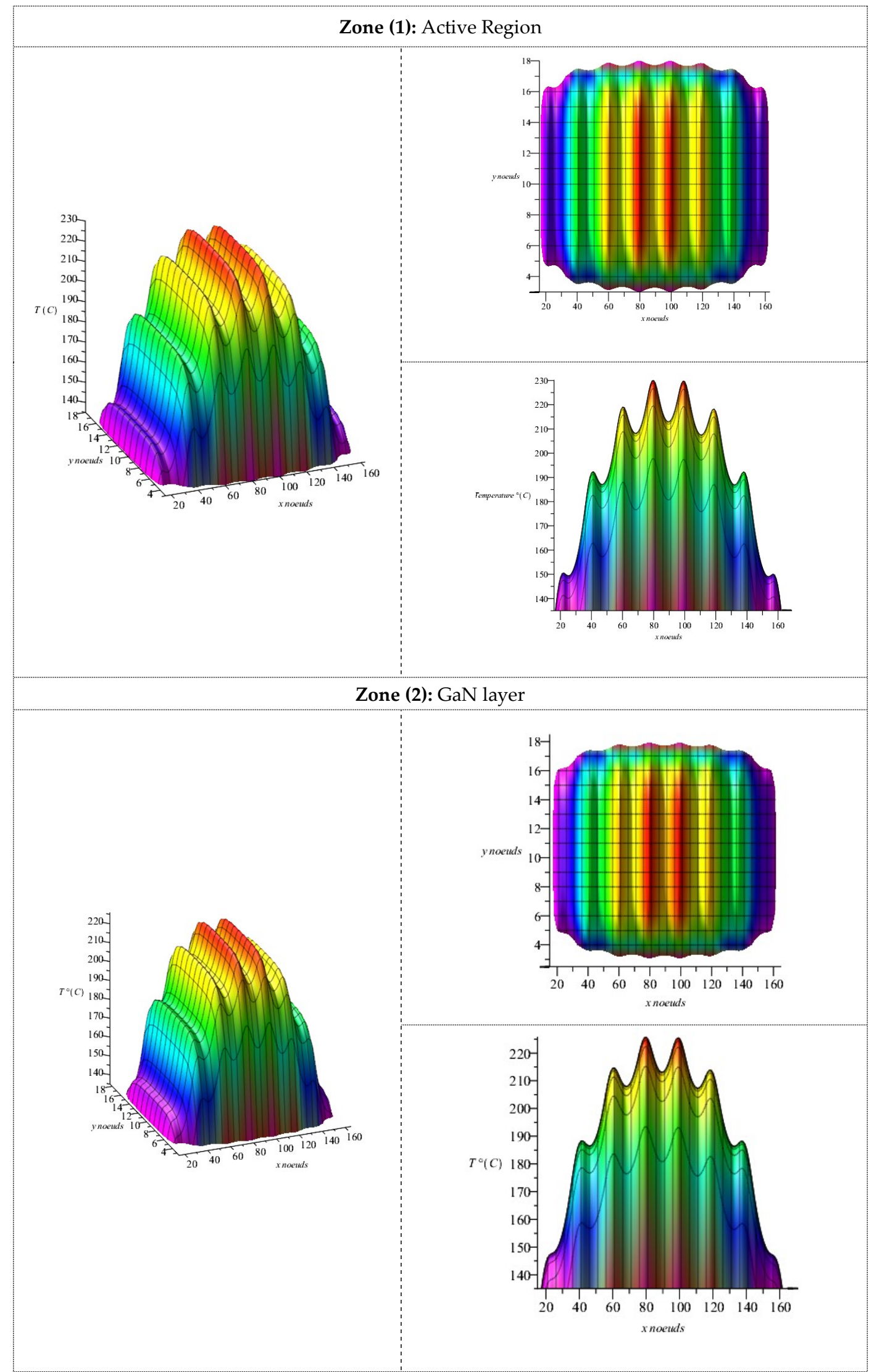

Figure 10. Cont. 


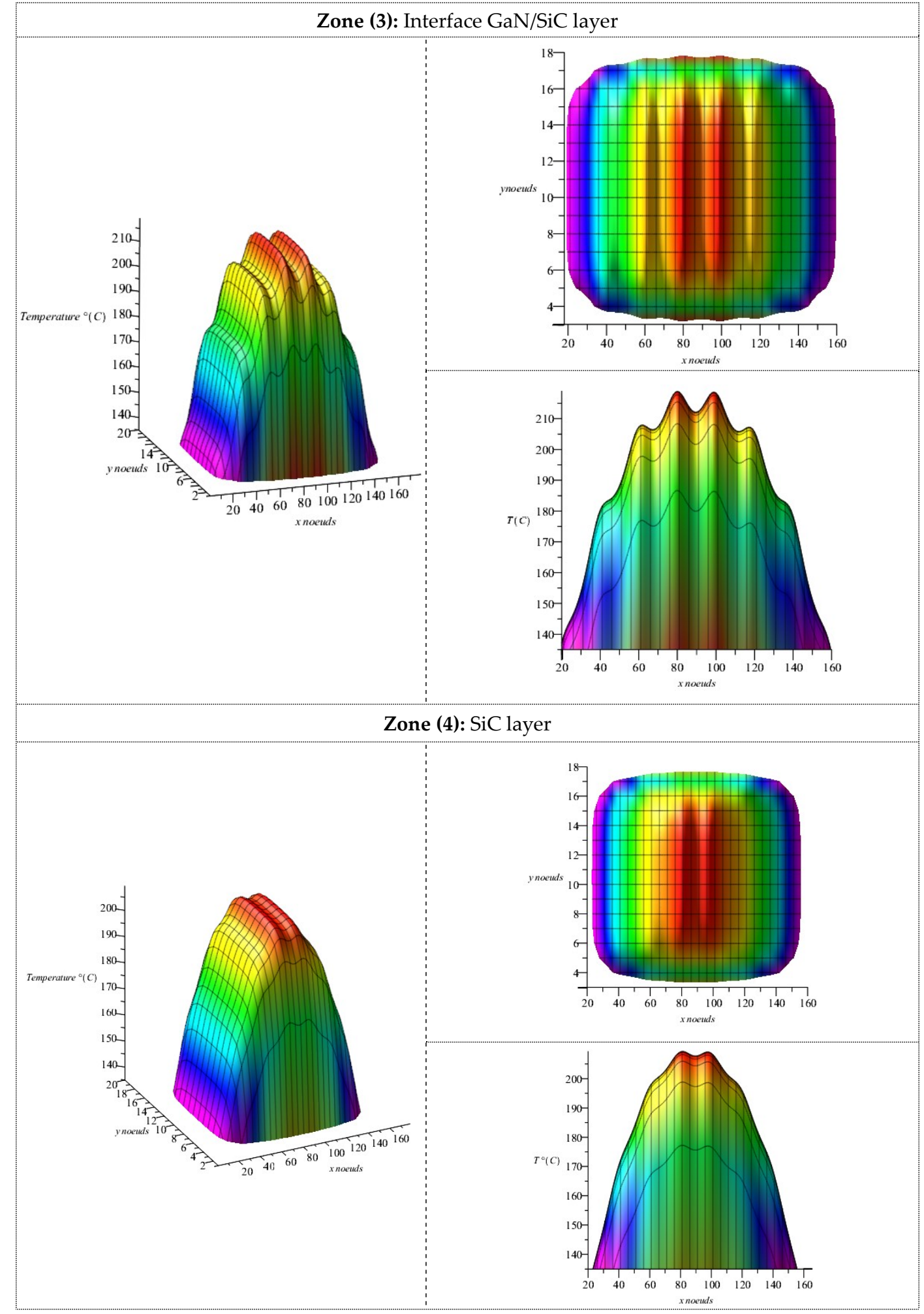

Figure 10. 3D-TLM simulation results through four chosen layers under excitation heat source. 


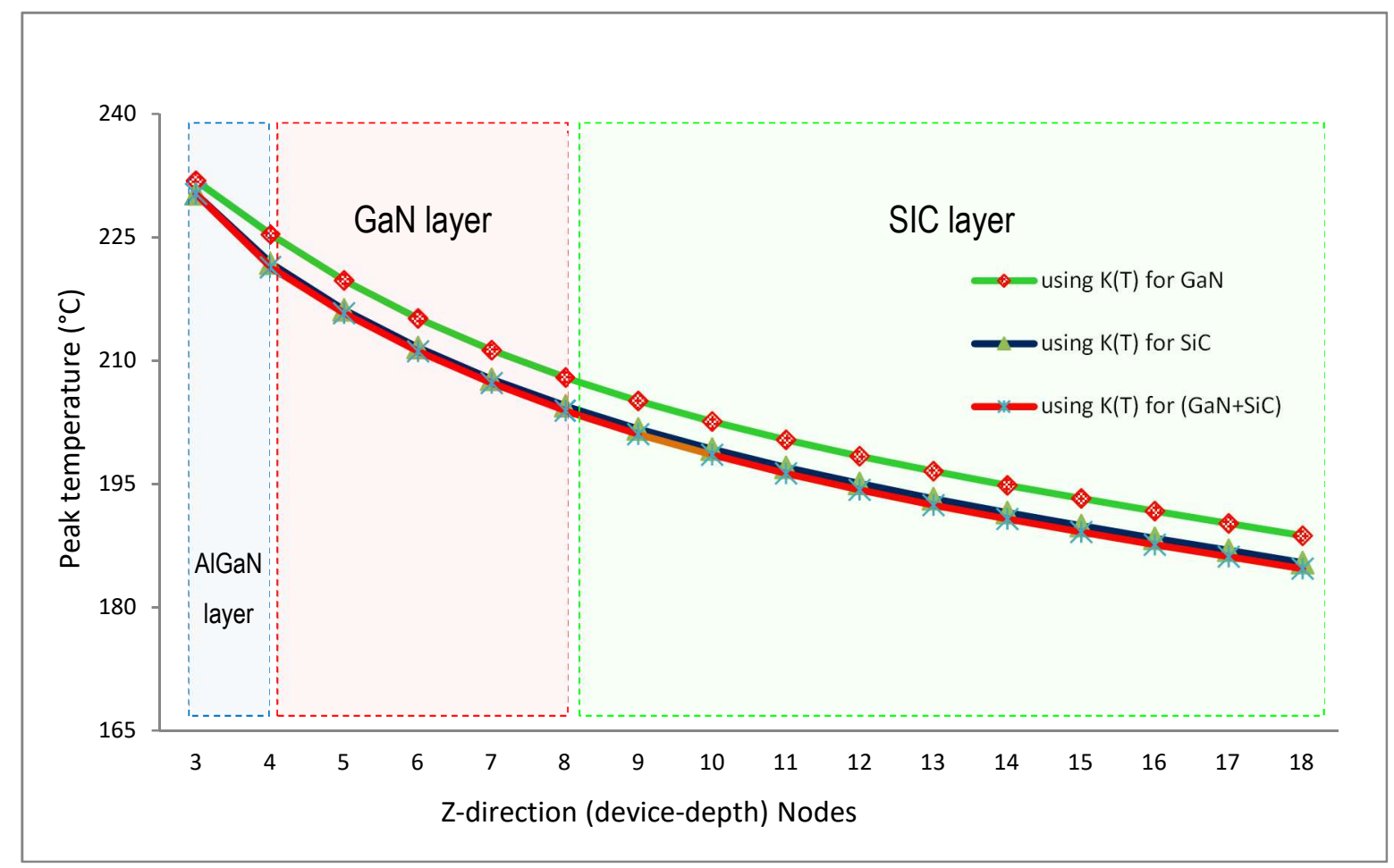

(a)

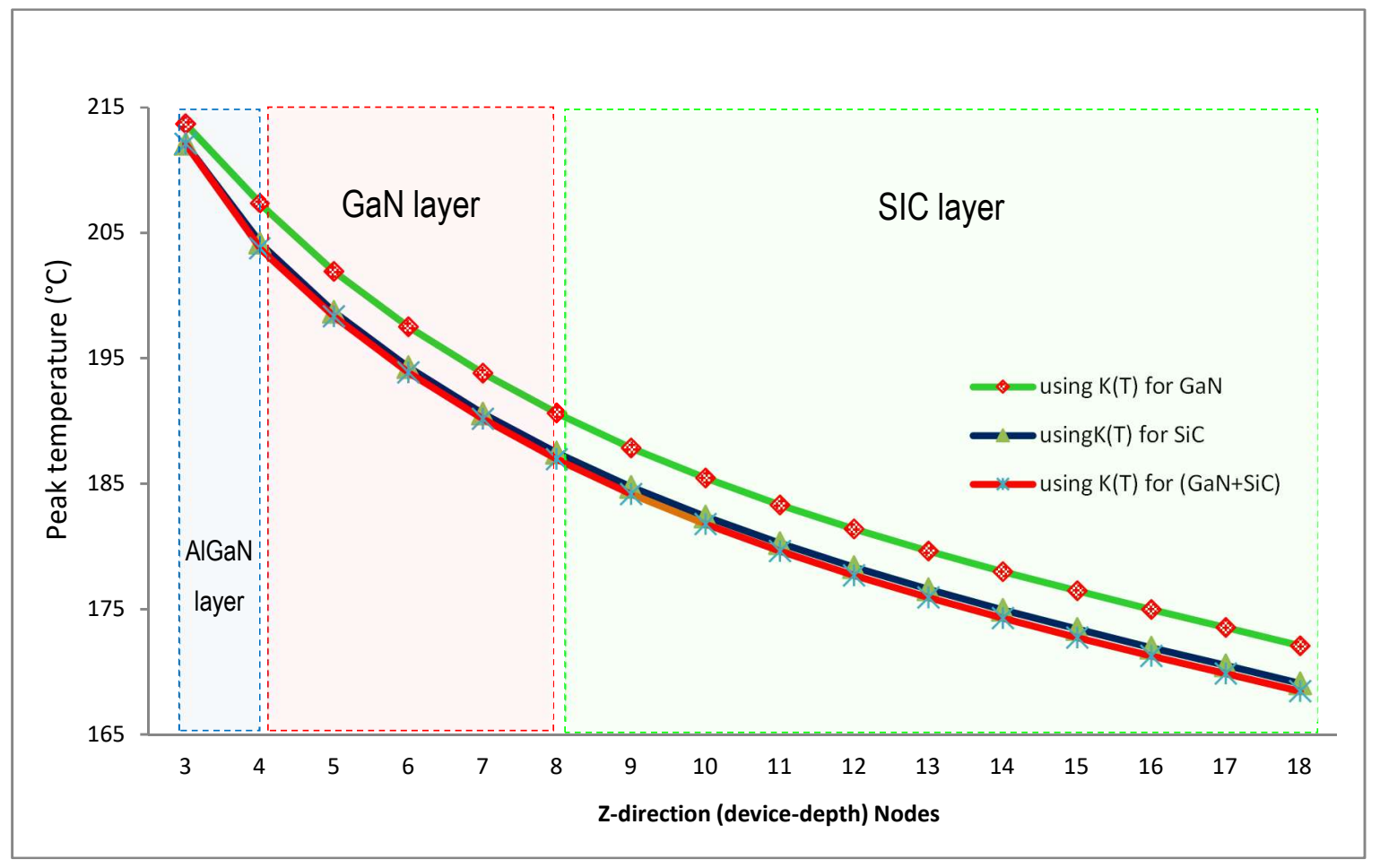

(b)

Figure 11. TLM-heat diffusion simulation through device layers under two types of excitation heat sources. (a) Nano scale hotspot; (b) Micro scale hotspot. 


\section{Conclusions}

With the increase in heat dissipation in high power amplifiers SSPA and the reduction in overall form factors, thermal study becomes a more and more important element of electronic product design. The three-dimensional simulations using Transmission Line Modelling are exposed and performed to investigate self-heating in the RF multi-finger AlGaN/GaN HEMTs devices and provides information on temperature distribution throughout the device. Its thermal behavior strongly depends on the substrate material on which the devices are grown. In addition, introducing Nano-scale excitation heat source in TLM simulation showed that channel temperature is much higher compared to the Micro-scale excitation heat source results. This is because the thermal behavior of AlGaN/GaN-based devices strongly depends on the value of thermal conductivity of various materials on which its structures are grown. But diffusivity alone is not a wholly valid parameter by which to select materials. The effect of the $\rho^{*} \mathrm{Cp}$ product (the heat necessary to raise the temperature of a unit volume of material) has a significant effect on the thermal profiles within miniaturized high-power amplifiers. In this paper, we used the Micro-Raman spectroscopy measurement to validate the TLM-3D thermal model. Good agreement between the measurement method and TLM simulation results is observed, with the maximum deviation between them at around $2.2 \%$. Since the TLM method allows for evaluating the temperature at any point of the structure, this numerical technique may be a good alternative design tool and seems to be efficient for understanding thermal behavior and management at each layer forming the device structure, even for a complex geometry structure and made-up with many different materials. The TLM method is explicit and unconditionally stable nature, with variable time-stepping capability and the easy incorporation of non-linear parameters as well as various boundary conditions.

Author Contributions: K. Belkacemi is the main author of the paper. R. Hocine supervised the entire research and provided valuable guidance to help with making crucial observations. She also directed the writing of this paper and its technical proofing.

Funding: This research received no external funding.

Acknowledgments: We would like to thank A. Boudjemai, head of space mechanical and propulsion service -CDS, for his encouragement, patience, insightful advice, and constructive feedback during the entire period of research work.

Conflicts of Interest: The authors declare no conflicts of interest.

\section{References}

1. Krishnamurthy, K.; Martin, J.; Landberg, B.; Vetury, R.; Poulton, M.J. Wideband 400 W pulsed power GaN HEMT amplifiers. In Proceedings of the 2008 IEEE MTT-S International Microwave Symposium Digest, Atlanta, GA, USA, 15-20 June 2008; pp. 303-306. [CrossRef]

2. Meneghesso, G.; Verzellesi, G.; Danesin, F.; Rampazzo, F.; Zanon, F.; Tazzoli, A.; Meneghini, M.; Zanoni, E. Reliability of GaN high electron-mobility transistors: State of the art and perspectives. IEEE Trans. Device Mater. Reliab. 2008, 8, 332-343. [CrossRef]

3. Mishra, U.K.; Parikh, P.; Wu, Y.-F. AlGaN/GaN HEMTs - an overview of device operation and application. Proc. IEEE, 2002, 90, 1022-1031. [CrossRef]

4. Naumov, A.V.; Kolomys, O.F.; Romanyuk, A.S.; Tsykaniuk, B.I.; Strelchuk, V.V.; Trius, M.P.; Avksentyev, A.Y.; Belyaev, A.E. Self-heating effects in AlGaN/GaN HEMT heterostructures: Electrical and optical characterization. Semicond. Phys. Quantum Electron. Optoelectron. 2015, 18, 396-402. [CrossRef]

5. Sheppard, S.T.; Doverspike, K.; Pribble, W.L.; Allen, S.T.; Palmour, J.W.; Kehias, L.T.; Jenkins, T.J. High-Power Microwave GaN/AlGaN HEMTs on Semi-Insulating Silicon Carbide Substrates. IEEE Electron Device Lett. 1999, 20, 161-163. [CrossRef]

6. Wu, Y.F.; Saxler, A.; Moore, M.; Smith, P.; Sheppard, S.; Chavarkar, M.; Wisleder, T.; Mishra, K.; Parikh, P. 30-W/mm GaN HEMTs by Field Plate Optimization. IEEE Electron Device Lett. 2004, 25, 117-119. [CrossRef]

7. Wu, Y.F.; Moore, M.; Saxler, A.; Wisleder, T.; Parikh, P. 40-W/mm Double Field-Plated GaN HEMTs. In Proceedings of the IEEE 64th Device Research Conference, State College, PA, USA, 26-28 June 2006; pp. 151-152. [CrossRef] 
8. Pengelley, R.S.; Wood, S.M.; Milligan, J.W.; Sheppard, S.T.; Pribble, W.L. A Review of GaN on SiC High Electron-Mobility Power Transistors and MMICs. IEEE Trans. Microw. Theory Tech. 2012, 60, 1764-1783. [CrossRef]

9. Lu, H.-L.; Zhang, Y.-M.; Zhang, Y.-M.; Che, Y. Electrothermal simulation of self-heating effects in $4 \mathrm{H}-\mathrm{SiC}$ MESFETs. Chin. Phys. B 2008, 17. [CrossRef]

10. Manoi, A.; Pomeroy, J.W.; Killat, N.; Kuball, M. Benchmarking of Thermal Boundary Resistance in AlGaN/GaN HEMTs on SiC Substrates: Implications of the Nucleation Layer Microstructure. IEEE Electron Device Lett. 2010, 31, 1395-1397. [CrossRef]

11. Sarua, A.; Hilton, J.; Hilton, K.P.; Wallis, D.J.; Uren, M.J.; Martin, T.; Kuball, M. Thermal Boundary Resistance between GaN and substrate in AlGaN/GaN Electronic Devices. IEEE Trans. Electron Devices 2007, 54, 3152-3158. [CrossRef]

12. Donmezer, N.F. Multiscale Electro-Thermal Modeling of AlGaN/GaN Heterostructure Field Effect Transistors. Ph.D. Thesis, Woodruff School of Mechanical Engineering, Atlanta, GA, USA, December 2013.

13. Yan, Z.; Liu, G.; Khan, J.M.; Balandin, A.A. Graphene quilts for thermal management of high power GaN transistors. Nat. Commun. 2012, 3, 827. [CrossRef] [PubMed]

14. Pomeroy, J.W.; Uren, M.J.; Lambert, B.; Kuball, M. Operating channel temperature in GaN HEMTs: DC versus RF accelerated life testing. Microelectron. Reliab. 2015, 55, 2505-2510. [CrossRef]

15. Agarwal, G.; Kazior, T.; Kenny, T.; Weinstein, D. Modeling and Analysis for Thermal Management in Gallium Nitride HEMTs using Microfluidic Cooling. J. Electron. Packag. 2017, 139, 1-11. [CrossRef]

16. Conway, A.M.; Asbeck, P.M.; Moon, J.S.; Micovic, M. Accurate thermal analysis of GaN HFETs. Solid-State Electron. 2008, 52, 637-643. [CrossRef]

17. Lin, H.C.; Khan, M.; Giao, T. Dynamic liquid crystal hotspot examination of functional failures on production testers. In Proceedings of the 20th Symposium for Testing and Failures Analysis, Los Angeles, CA, USA, 13-18 November 1994.

18. Kuball, M.; Pomeroy, J.W.; Rajasingam, S.; Sarua, A.; Uren, M.J.; Martin, T.; Lell, A.; Harle, V. High spatial resolution micro-Raman temperature measurements of nitride devices (FET and Light emitters). Phys. Status Solidi 2005, 202, 823-831. [CrossRef]

19. Shigekawa, N.; Shiojima, K.; Suemitsu, T. Optical study of high-biased AlGaN/GaN high-electron-mobility transistors. J. Appl. Phys. 2002, 92, 531. [CrossRef]

20. Burzo, M.; Kamarov, P.; Raad, P. Noncontact transient temperature mapping of active electronic devices using thermoreflectance method. IEEE Trans. Compon. Packag. Technol. 2005, 28, 637-643. [CrossRef]

21. Heller, E.; Crespo, A. Electro-thermal modeling of multifinger AlGaN/GaN HEMT device operation including thermal substrate effects. Microelectron. Reliab. 2013, 75, 45-50. [CrossRef]

22. Kuball, M.; Rajasingam, S.; Sarua, A.; Uren, M.J.; Martin, T.; Hughes, B.; Hilton, K.; Balmer, R. Measurement of Temperature distribution in multifinger $\mathrm{AlGaN} / \mathrm{GaN}$ heterostructures field-effect transistors using micro-Raman specroscopy. Appl. Phys. Lett. 2003, 82, 124. [CrossRef]

23. Simms, R.J.T.; Pomeroy, J.W.; Uren, M.J.; Martin, T.; Kuball, M. Channel temperature determination in high-power AlGaN/GaN HFETs using electrical methods and Raman spectroscopy. IEEE Trans. Electron Devices 2008, 55, 478-482. [CrossRef]

24. Darwish, A.M.; Bayba, A.J.; Hung, H.A. Thermal Resistance Calculation of AlGaN-GaN Devices. IEEE Trans. Microw. Theory Tech. 2013, 52, 2611-2620. [CrossRef]

25. De Cogan, D.; John, S.A. The calculation of temperature distribution in punch-through structures during pulsed operation using the transmission line modeling (TLM) method. J. Phys. D Appl. Phys. 1982, 15, 1979-1990. [CrossRef]

26. De Cogan, D.; John, S.A. A two-dimensional transmission line matrix model for heat flow in power semiconductors. J. Phys. D Appl. Phys. 1985, 18, 507-516. [CrossRef]

27. De Cogan, D.; Henini, M. TLM modelling of the thermal behaviour of conducting films on insulating substrates. J. Phys. D Appl. Phys. 1987, 20, 1445-1450. [CrossRef]

28. Hocine, R.; Boudjemai, A.; Belkacemi, K.; Amrani, A. A Three-Dimensional TLM Simulation Method for Analysis of Thermal Effect in the Space Solar Panel. In Proceedings of the 7th International Conference on Recent Advances in Space Technologies (RAST), IEEE Conference Publications, Istanbul, Turkey, 16-19 June 2015; pp. 561-566. [CrossRef] 
29. Johns, P.B. A simple explicit and unconditionally stable numerical routine for the solution of the diffusion equation. Int. J. Numer. Methods Eng. 1977, 11, 1307-1328. [CrossRef]

30. Partridge, C.J.; Christopoulos, C.; Johns, P.B. Transmission line modelling of shaft dynamic systems. Proc. Inst. Mech. Eng. 1987, 201, 271-278. [CrossRef]

31. Trenkic, V.; Christopoulos, C.; Binner, J.G.P. The application of the transmission line modelling TLM method in combined thermal and electromagnetic problems. In Proceedings of the International Conference on Numerical Methods for Thermal Problems, Swansea, UK, 11-16 July 1993; pp. 1263-1274.

32. German, F.J.; Gothard, G.K.; Riggs, L.S.; Goggans, P.M. The calculation of radar crosssection (rcs) using the tlm method. Int. J. Numer. Model. 1989, 2, 267-278. [CrossRef]

33. Umashankar, K.; Taflove, A. A novel method to analyze electromagnetic scattering of complex objects. IEEE Trans. Electromagn. Compat. 1982, EMC-24, 397-405. [CrossRef]

34. Webb, P.W.; Russell, I.A.D. Application of the TLM Method to Transient Thermal Simulation of Microwave Power Transistors. IEEE Trans. Electron Devices 1995, 42, 624-631. [CrossRef]

35. Christopoulos, C. The Transmission-Line Modeling Method; IEEE/OUP Series on Electromagnetic Wave Theory; Oxford University Press: Oxford, UK, 1995; Chapter 7; pp. 167-176. ISBN 978-0780310179.

36. Gui, X.; Webb, P.W.; Gao, G.B. Use of the three-dimensional TLM method in the thermal simulation and design of semiconductor devices. IEEE Trans. Electron Devices 1992, 39, 1295-1301. [CrossRef]

37. Hocine, R.; Pulko, S.H.; satmbouli, A.B.; Saidane, A. TLM method for thermal investigation of IGBT modules in PWM mode. Microelectron. Eng. J. 2009, 86, 2053-2062. [CrossRef]

38. Kronberg, E.; Benneker, A.H. Notes on wave theory in heat conduction: A new boundary condition. Int. J. Heat Mass Transf. 1998, 41, 127-137. [CrossRef]

39. Freeman, J.C. Channel Temperature for Microwave AlGaN/GaN on SiC and Sapphire MMICs in High Power High Efficiency SSPAs; NASA/TM-2004-212900; National Aeronautics and Space Administration, Glenn Research Center: Cleveland, OH, USA, 2013.

40. Azarifar, M.; Donmezer, N. A roadmap for building thermal models for AlGaN/GaN HEMTs: Simplification and beyond. In Proceedings of the ASME 2016 Heat Transfer, Washington, DC, USA, 10-14 July 2016; Paper No. HT2016-7383. pp. 1-7. [CrossRef]

41. Zhang, G.; Feng, S.; Li, J.; Zhao, Y.; Guo, C. Determination of channel temperature for AlGaN/GaN HEMTs by high spectral resolution micro-Raman spectroscopy. J. Semicond. 2012, 33. [CrossRef]

42. Riedel, G.J.; Pomeroy, J.W.; Hilton, K.P.; Maclean, J.O.; Wallis, D.J.; Uren, M.J.; Martin, T.; Forsberg, U.; Lundskog, A.; Kakanakova-Georgieva, A.; et al. Reducing Thermal Resistance of AlGaN/GaN Electronic Devices Using Novel Nucleation Layers. IEEE Electron Device Lett. 2009, 30, 103-106. [CrossRef]

43. Riedel, G.J.; Pomeroy, J.W.; Hilton, K.P.; Maclean, J.O.; Wallis, D.J.; Uren, M.J.; Martin, T.; Kuball, M. Nanosecond Timescale Thermal Dynamics of AlGaN/GaN Electronic Device. IEEE Electron Device Lett. 2008, 29, 416-418. [CrossRef]

44. Nigam, A.; Bhat, T.N.; Rajamani, S.; Dolmanan, S.B.; Tripathy, S.; Kumar, M. Effect of self-heating on electrical characteristics of AlGaN/ GaN HEMT on Si (111) substrate. AIP Adv. 2017, 7, 085015. [CrossRef]

45. Weatherford, T.; Wang, Y.; Tracey, S. TCAD analysis of self heating in AlGaN/GaN HEMTs under pulsed conditions. In Proceedings of the Integrated Reliability Workshop Final Report, S. Lake Tahoe, CA, USA, 18-22 October 2009. [CrossRef]

46. Thermal3D. Available online: www.silvaco.co/products/vwf/atlas/thermal3d/thermal3d.html (accessed on 11 June 2018).

(C) 2018 by the authors. Licensee MDPI, Basel, Switzerland. This article is an open access article distributed under the terms and conditions of the Creative Commons Attribution (CC BY) license (http:/ / creativecommons.org/licenses/by/4.0/). 